\title{
Pengembangan Ranah Berpikir Tingkat Tinggi (HOTS) Menggunakan Exploding Box QR Sebagai Media Pembelajaran Interaktif Pemahaman Membaca Materi Bimbingan Konseling Kelompok Peserta Didik SMP Negeri 1 Madiun
}

\author{
Eko Setyorini \\ Smp Negeri 1 Madiun \\ echa.ayoen@gmail.com
}

\begin{abstract}
Abstrak
Tujuan penelitian ini adalah untuk mengetahui pengembangan ranah berfikir tingkat tinggi (HOTS) dengan menggunakan Exploding Box QR sebagai media pembelajaran interaktif pada pemahaman membaca materi bimbingan kelompok peserta didik Kelas VIIB SMP Negeri 1 Madiun Tahun Pelajaran 2018/2019. Media baca interaktif exploding box QR merupakan suatu benda berbentuk kubus dikemas secara modern dimodifikasi menjadi tampilan 3D berisi ringkasan materi dalam bentuk scan barcode QR. Penggunaan media baca exploding box QR pada kegiatan bimbingan kelompok untuk m engubah cara membaca materi bimbingan kelompok yang semula dengan buku teks diganti menggunakan media baca exploding boxQR. Dampak penggunaan Media baca Interaktif exploding box QR adalah pemahaman materi dan kemampuan berpikir HOTS dari 32 peserta didik Kelas VIIB nilai rata-rata kelas pada pertemuan pertama dengan nilai 73,6. Pada pertemuan kedua hasil nilai rata-rata kelas naik menjadi 79,9. Sedangkan jumlah peserta didik tuntas pada pertemuan pertama $63,6 \%$ dan yang tidak tuntas sebesar 36,4\%. Pada pertemuan kedua ketuntasan menjadi 28 peserta didik (87,5\%) dan hanya 4 peserta didik yang belum mencapai tingkat pemahaman sesuai dengan rata rata.Dapat disimpulkan bahwa peserta didik kelas VIIB SMP Negeri 1 Madiun yang mengalami ketuntasan pemahaman materi bimbingan kelompok serta mampu mengembangan keterampilan berpikir tingkat tinggi (HOTS) bagi peserta didik kelas VIIB SMP Negeri 1 Madiun. Penggunaan media baca exploding boxQR juga memunculkan dampak pengiring peserta didik menjadi lebih gemar membaca.
\end{abstract}

Kata kunci: Media Exploring Box QR; Membaca; Bimbingan Kelompok: HOTS.

\begin{abstract}
The purpose of this study was to determine the development of high-level thinking domains (HOTS) by using the Exploding Box QR as an interactive learning media on reading comprehension guidance material for students in Class VIIB of SMP Negeri 1 Madiun in 2018/2019 Academic Year. The interactive reading media QR box exploding is a cube shaped object packaged in a modern way modified into a 3D display containing a summary of material in the form of a $\mathrm{QR}$ barcode scan. The use of the $\mathrm{QR}$ exploding box reading media in group guidance activities is to change the way of reading group guidance material which was originally replaced by a text book using the QQ exploding reading media. The impact of using the interactive reading media QR box exploding is the understanding of the material and HOTS thinking ability of 32 students of Class VIIB grade average grade at the first meeting with a value of 73.6. At the second meeting the results of the grade average value rose to 79.9. While the number of students completed at the first meeting was $63.6 \%$ and incomplete at $36.4 \%$. At the second meeting completeness became 28 students $(87.5 \%)$ and only 4 students who had not reached the level of understanding in accordance with the average. It can be concluded that the VIIB grade students of SMP Negeri 1 Madiun are experiencing thorough understanding of group guidance material and are able to develop high-level thinking skills (HOTS) for grade VIIB students of SMP Negeri 1 Madiun. The use of exploding boxQR read media also raises the impact of accompaniment students become more fond of reading.
\end{abstract}

Keywords: Media Exploring Box QR; Read; Group Guidance: HOTS.

\section{PENDAHULUAN}

\section{A. Latar Belakang Masalah}

Membaca merupakan salah satu aspek yang sangat penting didalam kehidupan manusia. Dengan membaca, kemampuan berfikir dan bernalar seorang manusia akan berkembang. Rendahnya minat baca masyarakat Indonesia, berdasarkan hasil riset tahun 2016 dari CCSU dalam kategori negara-negara dengan tingkat budaya membaca yang baik menempatkan Indonesia di urutan 60 dari 61 negara yang diteliti
(Metro Tv News, 30 Agustus 2016). Tentunya hal ini merupakan sebuah ironi di dunia pendidikan Indonesia. Maka dari itu tentunya sebuah negara seharusnya memiliki sistem untuk membudayakan gemar membaca, menuju generasi unggul dengan budaya literasi serta masyarakat literat. Dalman (2014:150), menyatakan adanya suatu budaya baca yang secara masif akan memunculkan kebiasaan permanen, maka akan membuat seseorang secara langsung maupun tak langsung dapat memengaruhi 
minat baca semakin tinggi dan mampu merangsang daya berfikir tingkat tinggi.

Permasalahan tersebut juga dialami langsung oleh penulis selaku pendidik bimbingan konseling di SMP Negeri 1 Madiun bahwa kesadaran membaca peserta didik Kelas VIIB sangat kurang sehingga pemahaman membaca materi dalam proses bimbingan tidak dapat dipahami secara maksimal. Penulis melakukan observasi mengindikasikan bahwa sebagian besar peserta didik merasa bosan dan menganggap membaca materi dalam buku merupakan sesuatu tidak menarik dan menganggap bermain gawai lebih menyenangkan daripada membaca buku, terutama materi dalam layanan bimbingan konseling. Banyaknya lembaran buku yang perlu dibaca serta dipahami peserta didik dalam pemahaman membaca serta mematangkan konsep, maka diperlukan indikator keberhasilan mengenai sikap, pengetahuan, dan keterampilan peserta didik yang sesuai dengan kurikulum yang berlaku saat ini (Kemendikbud, 2013:5).

Peserta didik setelah membaca buku bacaaan hanya mampu mengingat, memahami dan menerapkan. Belum sampai pada tahap menganalisis, menilai, apa lagi menciptakan sesuatu dari buku bacaan yang telah dibaca. Hal inilah menjadi tantangan bagi pendidik bimbingan konseling untuk membuat suatu program yang diharapkan dapat membudayakan minat baca dan memberdayakan kemampuan berfikir tingkat tinggi peserta didik, terutama dalam proses kegiatan layanan bimbingan kelompok. Karena dengan membudayakan minat membaca diharapkan dapat menjadi langkah awal kesuksesan menuju generasi yang memiliki karakter literat. Lickona (dalam Megawangi, 2010: 75) mengajarkan dan memberi pengetahuan kepada peserta didik dapat diibaratkan seperti menulis diatas batu yang artinya akan selalu membekas sampai dia berusia tua. Jadi waktu yang tepat untuk membentuk karakter gemar membaca di mulai dari usia sekolah.

Hampir semua mata pelajaran di sekolah menuntut kegiatan membaca buku. Oleh karena itu berhasil ataupun gagalnya prestasi peserta didik salah satunya dipengaruhi aktivitas membacanya. Penulis berusaha membuat alternatif tindakan agar peserta didik termotivasi untuk gemar membaca. Pembelajaran yang memicu peserta didik untuk berfikir tingkat tinggi menuntut penggunaan strategi pembelajaran yang berorientasi pada peserta didik aktif, sehingga peserta didik memiliki kesempatan untuk mengamati, menanya, menalar, mencoba, dan mengkomunikasikan. Pendekatan semacam ini sangat sesuai dengan harapan kurikulum 2013. Higher Order Thinking Skill (HOTS) adalah keterampilan berfikir tingkat tinggi yang menuntut pemikiran secara kritis, kreatif, analitis, terhadap informasi dan data dalam memecahkan permasalahan (Barratt, 2014: 32). Adapun media yang digunakan untuk menjawab tantangan tersebut adalah dengan pengembangan ranah berfikir tingkat tinggi (HOTS) menggunakan Exploding Box $Q R$ sebagai media pembelajaran interaktif pemahaman membaca materi bimbingan kelompok peserta didik Kelas VIIB SMP Negeri 1 Madiun. Sebuah media baca inovatif yang praktis, menarik, dan menyenangkan bagi peserta didik dalam Layanan Bimbingan Kelompok.

\section{B. Tujuan}

Tujuan umum dari penulisan ini yaitu untuk mengetahui pengembangan ranah berfikir tingkat tinggi (HOTS) dengan menggunakan Exploding Box $Q R$ sebagai media pembelajaran interaktif pemahaman membaca materi bimbingan kelompok peserta didik Kelas VIIB SMP Negeri 1 Madiun. Tujuan khusus dari penulisan ini yaitu mendeskripsikan perubahan aktivitas peserta didik dengan menerapkan media pembelajaran interaktif Exploding Box $Q R$ melalui kegiatan bimbingan kelompok.

\section{Manfaat}

1. Bagi Peneliti

a. meningkatkan kemampuan pedagogik dan professional guru,

b. meningkatkan kemampuan guru menciptakan inovasi media pembelajaran/Layanan,

c. meningkatkan kemampuan guru Bimbingan Konseling dalamdi Layanan bimbingan kelompok.

2. Bagi Peserta Didik

a. meningkatkan kemampuan peserta didik agar gemar membaca.

b. meningkatkan kemampuan peserta didik dalam mengatasi hambatan belajar yaitu membaca.

3. Bagi Sekolah

Penciptaakn karya inovasi berupa media interaktif Exploding Box QR ini diharapkan dapat berkontribusi pada usaha peningkatan kualitas dan kuantitas dalam pembelajaran/layanan Bimbingan Konseling di sekolah.

4. Bagi Teman Sejawat

a. memberikan ide bagi rekan sejawat untuk menciptakan inovasi sejenis dalam pembelajaran/layanan Bimbingan Konseling,

b. memberikan kesempatan kepada rekan sejawat untuk lebih menyempurnakan Media Exploding Box $Q R$ dapat membantu peserta didik lebih mudah memahami materi Bimbingan Kelompok.

\section{KAJIAN TEORI}

Belajar merupakan usaha yang dilakukan seseorang untuk mencapai sebuah tujuan, usaha tersebut mengarahkan seseorang dari keadaan tidak bisa menjadi bisa, dan dari tidak tahu menjadi tahu yang tidak terlepas dari factor internal dan eksternal yang mempengaruhi proses dan hasilnya. Pembelajaran adalah suatu sistem atau proses membelajarkan peserta didik yang dirancang, dilaksanakan, dan dievaluasi secara sistematis agar peserta didik mencapai tujuan pembelajaran yang diharapkan. Pembelajaran memiliki beberapa komponen antara lain tujuan pembelajaran, materi pembelajaran, strategi dan metode pembelajaran, media pembelajaran, dan evaluasi pembelajaran. Pembelajaran memproses input agar menghasilkan output yang diinginkan.

Berpikir merupakan bagian dari ranah kognitif yang diklasifikasikan Bloom ke dalam enam tingkatan proses kognitif: pengetahuan (knowledge); pemahaman (comprehension); penerapan (application); mengalisis (analysis); menilai (evaluation); dan mencipta (creat). 
(Anderson, 2010:46). Tingkatan tersebut menunjukkan bahwa berpikir untuk mengetahui merupakan tingkatan berpikir yang paling rendah (Lowerer) sedangkan menilai merupakan tingkatan berpikir paling tinggi (Higherer).

Higher Order Thinking Skill (HOTS) adalah keterampilan berfikir tingkat tinggi yang menuntut pemikiran secara kritis, kreatif, analitis, terhadap informasi dan data dalam memecahkan permasalahan (Barratt, 2014: 32). Berfikir tingkat tinggi merupakan jenis pemikiran yang mencoba mengeksplorasi pertanyaan-pertanyaan mengenai pengetahuan yang ada terkait isu-isu yang tidak didefinisIkan dengan jelas dan tidak memiliki jawaban yang pasti (Haig, 2014:78).

Mengembangkan pemikiran kritis menuntut latihan menemukan pola, menyusun penjelasan, membuat hipotesis, melakukan generalisasi, dan mendokumentasikan temuan-temuan dengan bukti (Eggen, 2012: 261). Hal ini menunjukkan bahwa pembelajaran memicu peserta didik untuk berfikir tingkat tinggi menuntut penggunaan strategi pembelajaran yang berorientasi pada peserta didik aktif, sehingga peserta didik memiliki kesempatan untuk mengamati, menanya, menalar, mencoba, dan mengkomunikasikan. Pendekatan semacam ini sangat sesuai dengan harapan kurikulum 2013.

\section{HASIL DAN PEMBAHASAN}

Penggunakan media baca interaktif exploding box QR untuk mengembangkan kemampuan ranah berfikir tingkat tinggi (HOTS) dalam membaca materi bimbingan kelompok berdasarkan beberapa alasan, diantaranya sebagai berikut:

1. Rendahnya minat membaca serta pemahaman materi tingkat lowwer

Kondisi peserta didik menganggap membaca buku adalah kegiatan membosankan, ribet, dan memakan waktu lama dan untuk membaca materi didalam buku menjadi suatu kendala bagi pendidik untuk mengajak dan membudayakan kegiatan gemar membaca. Kecenderungan peserta didik menjadi kurang gemar membaca karena minimnya dorongan motivasi dari orangorang disekelilingnya. Sepatutnya lingkungan peserta didik terus memotivasi agar peserta didik semakin berminat untuk membaca. Hal ini sesuai pendapat Dalman (2014:141) bahwa minat membaca adalah suatu aktivitas dilakukan seseorang dengan penuh ketekunan untuk menemukan makna dari suatu tulisan dan mendapatkan informasi untuk menambah intelektualitasnya lalu mampu merangsang ide-ide dari dalam dirinya. Peserta didik setelah membaca buku bacaaan hanya mampu mengingat, memahami dan menerapkan belum sampai pada tahap menganalisis, menilai, apalagi menciptakan sesuatu ide dari buku yang telah dibaca.
2. Media buku yang kurang menarik

Bentuk fisik buku teks atau buku paket yang kurang menarik dan terlihat tebal terkesan menjadi barang yang kurang mendapat apresiasi dikalangan peserta didik. Padahal untuk meningkatkan minat membaca peserta didik harus dikenalkan dengan objek tertentu. Selain itu penggunaan buku teks masih menjadi satu-satunya acuan oleh pengajar untuk memberikan informasi kepada peserta didik. Hal ini sesuai pernyataan Farida Rahim (2008:85) bahwa pada praktiknya pendidik sering menggunakan buku teks sebagai bahan ajar satu-satunya di kelas.

3. Peserta didik yang lebih senang dengan gawai Seiring dengan kemajuan teknologi yang berkembang secara pesat, perubahan paradigma sumber belajar peserta didik juga berbeda. Penggunaan gawai sangat digemari oleh semua kalangan masyarakat. Kegiatan membaca yang semula hanya mengandalkan perantara kertas. Tetapi saat ini dapat dengan mudah menggunakan gawai. Oleh karenanya mulai saat ini penggunaan gawai harus dioptimalkan sebagai sarana pengganti buku dan pendidik harus dapat membuat alternatif cara membuat peserta didik gemar membaca materi pelajaran dengan media gawai. Hal tersebut didukung dari pendapat Dewi Salma (2013:18) penggunaan gawai sebagai alat menyampaikan materi pelajaran karena mudah dimengerti dan dipahami. Media baca interaktif exploding box $Q R$ dibuat untuk meningkatkan minat baca dan pengembangan ranah berfikir tingkat tinggi (HOTS) peserta didik kelas VIIB SMP Negeri 1 Madiun. Sebuah media menggabungkan seni melipat kertas berbentuk kotak kubus yang mirip kado ulang tahun yang didalam kotak kubus terdapat kumpulan-kumpulan materi bimbingan kelompok yang telah dimodifikasi sebagus dan semenarik mungkin dengan teknologi yang mengandalkan gawai yang berbasis teknologi QR.

Tujuan Media baca interaktif exploding box $Q R$ untuk mengubah paradigma belajar peserta didik yang tidak suka membaca kemudian menjadi gemar membaca serta mampu berfikir secara HOTS. Solusi yang ditawarkan dengan cara mengubah tampilan isi buku yang penuh dengan tulisan diubah menjadi gambar-gambar menarik dan simbol keterwakilan dari tulisan. Di dalam kotak terdapat kumpulan materi berupa materi bimbingan kelompok, permainan mengisi teka-teki silang yang berkaitan dengan materi pembelajaran. Peserta didik akan dibuat penasaran dengan tampilan luar kotak berbentuk kubus. Kemudian setelah dibuka maka akan terlihat gambar dan tulisan yang didesain menarik agar peserta didik antusias mencermati dan mengamati content pelajaran yang disampaikan di dalam kotak. Peserta didik akan lebih mudah untuk menemukan, mencatat materi penting dan mengerjakan lembar kerja peserta didik yang berbentuk teka-teki silang di exploding box. Implementasi 
peserta didik diperkenalkan bahwa teknologi saat ini bisa dimanfaatkan untuk belajar secara menyenangkan. Tidak hanya untuk bermain saja Di dalam Media Baca Interaktif exploring box $Q R$ dilengkapi barcode. Pada media kertas Barcode, proses memindai barcode bisa memanfaatkan gawai. Setelah barcode $Q R$ berhasil dipindai secara otomatis langsung terhubung ke channel yang tersedia seperti gogle drive, YouTube, atau facebook berisi materi, kuis, atau video pembelajaran tentang materi yang dibahas dalam bimbingan kelompok. Kartu barcode $Q R$ ini menjadi satu kesatuan dengan media exploring box. Peserta didik mengambilnya di salah satu bagian sisi exploring box dengan nama “Tahukah Kamu?'.Dengan menggunakan kertas Barcode $Q R$ keterampilan peserta didik dalam menggunakan piranti era digital semakin meningkat dan lebih bijak menggunakannya.

\section{Gambar dan Tabel}

Tabel 1. Format Tabel

\begin{tabular}{|c|c|c|c|c|c|c|c|c|c|}
\hline \multirow{2}{*}{$\begin{array}{c}\text { SKB } \\
\text { M }\end{array}$} & \multicolumn{3}{|c|}{ PRASIKLUS } & \multicolumn{3}{c|}{ SIKLUS I } & \multicolumn{3}{|c|}{ SIKLUS II } \\
\cline { 2 - 9 } & $\mathbf{f}$ & $\%$ & Ket & f & $\%$ & Ket & f & $\%$ & Ket \\
\hline$<80$ & 1 & 45, & BLM & 1 & 36, & BL & 4 & 12, & BLM \\
& 4 & 5 & & 2 & 40 & M & & 50 & \\
\hline \multirow{2}{*}{$\geq 80$} & 1 & 54, & Tunt & 2 & 63, & $\begin{array}{c}\text { Tu } \\
\text { nta }\end{array}$ & 2 & 87, & Tuntas \\
& 8 & 50 & as & 0 & 60 & s & 50 & \\
\hline $\begin{array}{c}\text { Juml } \\
\text { ah }\end{array}$ & 3 & & & 3 & & & 3 & & \\
\hline
\end{tabular}

Gambar 1. Hasil Ketuntasan Belajar Peserta didik Kelas VIIB

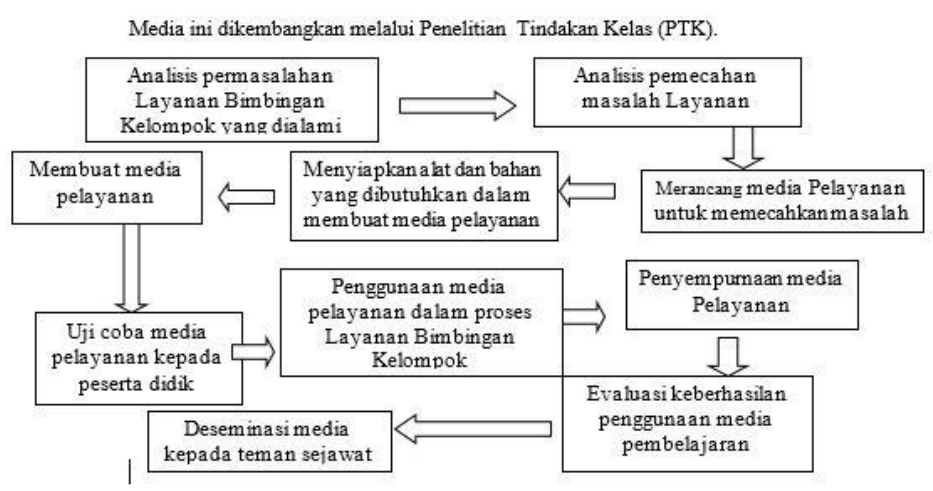

\section{PENUTUP}

\section{Simpulan}

Media Baca Interaktif Exploding Box $Q R$ merupakan media pembelajaran berbentuk kubus tampilan 3D untuk penyampaian informasi Layanan Bimbingan Kelompok dengan mengubah cara membaca materi bimbingan kelompok yang semula berupa buku teks diganti dengan menggunakan media baca exploding box $Q R$ menggunakan scan barcode $Q R$ untuk pengembangan keterampilan berfikir tingkat tinggi HOTS pada peserta didik kelas VIIB SMP Negeri 1 Madiun.
Dapat disimpulkan bahwa penggunaan Media baca interaktif Exploding Box $Q R$ dapat meningkatkan budaya literasi untuk mewujudkan peserta didik yang literat dan meningkatkan budaya gemar membaca. Selain itu dampak lainnya adalah adanya pengembangan ranah berfikir tingkat tinggi (HOTS) dengan meningkatnya kemampuan mengalisis/mengindetifikasi, menilai serta menciptakan/merancang dari hasil membaca buku pada peserta didik kelas VIIB SMP Negeri 1 Madiun.

\section{Saran}

Penggunaan Media baca interaktif 3D Berupa exploring box $Q R$ perlu pendekatan baru terhadap peserta didik.

Perlu pengaturan posisi peserta didik dalam menggunakan media baca interaktif exploding box QR pada waktu kegiatan pembelajaran.

\section{DAFTAR PUSTAKA}

Andriyadi, Anggi. (2011). Barcode QR Lampung: AR Team.

Asyhar, Rayandra. (2012). Kreatif Mengembangkan Media Pembelajaran. Jakarta : Referensi.

BSNP. (2006). Panduan Penyusunan Kurikulum

Tingkat Satuan Pendidikan Jenjang Pendidikan Dasar dan Menengah. Jakarta : DEPDIKNAS.

Dalman. (2014). Ketrampilan Membaca. Jakarta: Rajawali Pers.

Daryanto. (2013). Media Pembelajaran. Yogyakarta: Gava Media.

Gumono. (2014). Profil Kemampuan Membaca Peserta Didik Sekolah Dasar di Provinsi Bengkulu. Bengkulu: Lentera Pendidikan

Kemendikbud. (2013). Panduan Penilaian di SD. Jakarta: KEMDIKBUD.

Megawangi, Ratna. (2010). Pendidikan Karakter Anak Usia Dini. Jakarta: Indonesia Heritage Fundation.

Metro TV News. (2016). Indonesia peringkat dua terbawah dalam survei terkait minat baca., http://m.metrotvnews.com/internasional/dunia/Wb7Ordab -indonesia-peringkat-dua-terbawah-dalam-survei-terkaitminat-baca, diunduh di Semarang, 15 September 2018.

Munadi, Yudhi. (2012). Media Pembelajaran Sebuah Pendekatan Baru. Jakarta: Gaung Persada Press. 
Rahim, Farida. (2008). Pengajaran Membaca di Sekolah Dasar. Jakarta: Bumi Aksara

Salma, Dewi. (2013). Mozaik Teknologi Pendidikan elearning. Jakarta: Kencana Prenada Media Group.

Somadoyo. (2011). Strategi dan Teknik Pembelajaran Membaca. Yogyakarta: Graha Ilmu.

Sudjana, Nana. (2011). Dasar-Dasar Proses Belajar Mengajar. Bandung: Sinar Baru Algesindo.

Sundayana, Rostina. (2013). Media Pembelajaran Matematika. Bandung : Alfabeta.

Susanto, Ahmad. (2013). Teori Belajar dan Pembelajaran di Sekolah Dasar. Jakarta: Kencana Prenadamedia Group. 